\title{
Review
}

\section{Antithrombotic Therapy in Carotid Artery Stenosis: An Update}

\author{
Maurizio Paciaroni ${ }^{a} \quad$ Julien Bogousslavsky ${ }^{b}$ \\ a Stroke Unit and Division of Cardiovascular Medicine, Santa Maria della Misericordia Hospital, University of Perugia,

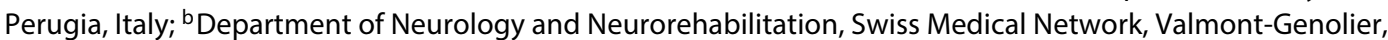 \\ Glion sur Montreux, Switzerland
}

\section{Key Words}

Carotid stenosis · Prevention · Antiplatelet · Surgery

\begin{abstract}
Carotid stenosis is generally associated with high risks of stroke and vascular events. In asymptomatic and symptomatic patients, with or without revascularization, optimal managements of carotid artery stenosis require the use of medications or lifestyle modifications (stopping smoking and monitoring hypertension, hyperlipidemia, and diabetes) to control the processes associated with atheroma to reduce the risk of embolic events. Moreover, antiplatelet therapy should be considered. There is little evidence that antiplatelet therapy is beneficial in preventing stroke or the progression of stenosis in asymptomatic patients, whereas, evidence of a benefit from antiplatelet therapy for secondary prevention of recurrent stroke in symptomatic patients with carotid atherosclerosis is more robust. Also, in patients undergoing carotid endarterectomy, perioperative anti-
\end{abstract}

thrombotic therapy should include aspirin, while the addition of clopidogrel should be decided case-by-case. Furthermore, perioperative antithrombotic therapy in patients undergoing carotid stenting should consist a combination of aspirin plus clopidogrel.

(c) 2014 S. Karger AG, Basel

\section{Introduction}

The management of internal carotid stenosis is an important element in stroke prevention and has been the subject of extensive clinical investigation, including multiple controlled randomized trials. In fact, multiple treatments have been shown to be beneficial in treating carotid disease. Being so, we have carried out this review on the best medical therapy available, especially antithrombotic treatment. Moreover, we reported the influence of this treatment in patients with symptomatic and asymptomatic stenosis, before and after revascularization.

\section{KARGER 125}

(C) 2014 S. Karger AG, Basel

0014-3022/14/0732-0051\$39.50/0

E-Mail karger@karger.com

www.karger.com/ene
Maurizio Paciaroni

Stroke Unit and Division of Internal and Cardiovascular Medicine

Santa Maria della Misericordia Hospital, University of Perugia

Via G. Dottori 1, IT-06100 Perugia (Italy)

E-Mail maurizio.paciaroni@unipg.it 


\section{Carotid Atherosclerosis}

About $20 \%$ of ischemic stokes are estimated to be the result of carotid artery occlusive disease [1], and nearly $80 \%$ of these strokes occur in asymptomatic patients without histories of stroke or transient ischemic attack (TIA) [2]. Clinically relevant stenosis, which increases the risk of stroke, is defined as a stenosis greater than $50 \%$ [3]. In the general population, the prevalence of $\geq 50 \%$ carotid stenosis ranges from $0.2 \%$ in males aged up to 50 to $7.5 \%$ in males aged up to 80 . For females, this prevalence increases from 0 to 5\% [4]. This prevalence is higher in all patients with additional atherosclerotic lesions: an estimated $11-26 \%$ of patients with coronary artery disease and $25-49 \%$ with peripheral artery disease have asymptomatic carotid artery stenosis [5]. A number of risk factors have been associated with the development and presence of asymptomatic carotid stenosis with age and male sex appearing to be the most determining [5]. Diabetes mellitus, hypertension, smoking, and dyslipidemia are other modifiable risk factors associated with carotid atherosclerosis [6].

The estimated annual risks of vascular events in patients with asymptomatic $\geq 50 \%$ carotid stenosis are stroke $2 \%$, coronary ischemic event $7 \%$, stroke mortality $0.6 \%$, and overall mortality $4-7 \%$ [7]. In these asymptomatic patients, carotid endarterectomy can be performed when the rate of perioperative stroke and death are no more than $3 \%$, as randomized trials have shown a significant benefit from surgery over 5 years follow-up, with an overall reduction in the risk of stroke of about 6\% [8]. Carotid stenting is not recommended for asymptomatic patients at this time [9].

The prognosis of patients with symptomatic carotid stenosis is dramatically different from that of patients with asymptomatic carotid stenosis because the risk of stroke after a TIA or stroke is very high particularly in patients with severe carotid stenosis [10]. Pooled data from the major carotid surgery trials have shown that even if great care is taken to optimize the modifiable risk factors, using treatment therapy available at the time, patients with carotid stenosis greater than $50 \%$ have a 5 -year cumulative risk of $21.2 \%$ for ipsilateral stroke if treated medically alone [11]. In these patients, endarterectomy was reported to reduce the 5-year absolute risk of ipsilateral ischemic stroke and any operative stroke or death in patients with $50-69 \%$ stenosis by $4.6 \%$ and was highly beneficial in patients with 70-99\% stenosis with an absolute risk reduction of $16 \%$ [12]. However, no benefit in patients with a near occlusion was observed. The role of carotid stenting has still not been clearly defined and there is no convincing data demonstrated that this procedure is superior to endarterectomy even for high-risk patients [13].

\section{Medical Management of Patients with Carotid Atherosclerosis Focusing on Anti-Thrombotic Therapy}

In asymptomatic and symptomatic patients, with or without revascularization, the optimal management of carotid artery stenosis requires the use of medications or lifestyle modifications (stopping smoking and monitoring hypertension, hyperlipidemia, and diabetes) to control the processes that cause atheroma as well as the use of antiplatelet agents to reduce the risk of embolic events [14]. Regarding antithrombotic therapy, a differentiation between asymptomatic and symptomatic stenosis needs to be done.

\section{Risk Factors Control}

Multiple studies on statins have reported a regression of carotid intimal medial thickness, which is a strong predictor of carotid atherosclerosis and also a risk factor for stroke [15-17].

The Heart Protection Study (HPS), that randomized 20,536 high-risk patients with a history of ischemic heart disease and other vascular diseases including ischemic stroke or diabetes mellitus, to simvastatin $40 \mathrm{mg}$ once a day or placebo, reported a significant decrease in the rate of carotid endarterectomy in those patients treated with statins (RRR 0.54, 95\% CI 0.38-0.77) [18]. Likewise, the SPARCL trial (The Stroke Prevention by Aggressive Reduction in Cholesterol Levels) randomized 4,731 patients with recent stroke or TIA having LDL-cholesterol between 100 and $190 \mathrm{mg} / \mathrm{dl}$ without a history of ischemic coronary disease to atorvastatin $80 \mathrm{mg}$ once a day or placebo. Also this study reported a reduced rate of revascularization including carotid revascularization in those patients treated with statins (HR 0.55, 95\% CI 0.43-0.72) [19].

Clinical trials and epidemiological studies have evidenced that lowering blood pressure reduces the risk of both, first and recurrent stroke. Lowering blood pressure through antihypertensive treatments is recommended for individuals who have hypertension along with asymptomatic carotid stenosis. At the same time, Rothwell and colleagues have reported that the relationship between blood pressure and stroke risk is less predictable for pa-
52 
tients with extracranial symptomatic carotid stenosis compared to general populations of patients with stroke or transient ischemic attack [20]. Nonetheless, it is considered safe to treat hypertension in the vast majority of patients with stroke or transient ischemic attack even though a negative relationship between blood pressure and stroke risk in the small proportion of patients who have bilateral $70 \%$ or greater carotid stenosis has been reported. This suggests that aggressive blood pressure lowering may not be advisable for the latter group; instead, they require revascularization to render hypertension treatment safer.

\section{Symptomatic Carotid Stenosis}

Evidence supporting the use of antithrombotic therapy for secondary prevention of recurrent stroke in symptomatic patients with carotid atherosclerosis is more robust than that available for asymptomatic patients. Specifically, the Antiplatelet Trialists Collaboration reported that antiplatelet therapy is beneficial in patients with recent stroke and TIA, although patients with symptomatic carotid stenosis were not separately identified in these analyses [21]. Moreover, aspirin and the combination of aspirin and extended released dipyridamole, clopidogrel, and triflusal have been shown to be effective as antiplatelet agents in long-term secondary prevention of ischemic stroke [22] and all are considered acceptable options for initial therapy. Aspirin (81-300 mg) has also been shown to be safe and effective in the acute postischemic phase (first $48 \mathrm{~h}$ ) and should be started immediately in patients with ischemic stroke or TIA. Regarding the combination of aspirin and clopidogrel, there is some evidence that it is significantly better than aspirin alone at preventing embolization from recently symptomatic carotid stenosis. In fact, a combination of clopidogrel and aspirin cohort had fewer patients with microembolic signals (MESs), fewer MESs per $h$, and fewer strokes compared to patients treated with aspirin alone in the first week after the initial clinical presentation [23]. Likewise, the CHANCE trial evidenced that patients with TIA or minor stroke who could be treated within $24 \mathrm{~h}$ after the onset of symptoms, the combination of clopidogrel and aspirin better reduced the risk of stroke in the first 90 days and did not increase the risk of hemorrhage compared to aspirin alone. This randomized, double-blind, placebo-controlled trial conducted at 114 centers in China, randomly assigned 5,170 patients within $24 \mathrm{~h}$ after the onset of minor ischemic stroke or high-risk TIA to combination therapy with clopidogrel and aspirin

Antithrombotic Therapy in Carotid

Artery Stenosis: An Update (clopidogrel at an initial dose of $300 \mathrm{mg}$, followed by $75 \mathrm{mg}$ per day for 90 days, plus aspirin at a dose of 75 mg per day for the first 21 days) or to placebo plus aspirin (75 mg per day for 90 days). Stroke occurred in $8.2 \%$ of patients in the clopidogrel-aspirin group, compared to $11.7 \%$ in the aspirin group (hazard ratio, 0.68 ; 95\% confidence interval, $0.57-0.81 ; \mathrm{p}<0.001)$. Moderate or severe hemorrhage occurred in seven patients $(0.3 \%)$ in the clopidogrel-aspirin group and in eight $(0.3 \%)$ in the aspirin group ( $\mathrm{p}=0.73)$; the rate of hemorrhagic stroke was $0.3 \%$ for each group [24]. The CHANCE trial results are based upon a Chinese-only population where the prevalence of extracranial atherosclerosis is known to be very low as compared to intracranial atherosclerosis, thus the results should not be considered applicable to other populations.

Oral anticoagulants have been shown to be less effective than antiplatelet therapy for secondary prevention of neurological events in patients with carotid atherosclerosis without a history of atrial fibrillation and therefore, it is not indicated in patients with symptoms of cerebral ischemia $[25,26]$.

\section{Asymptomatic Carotid Stenosis}

A meta-regression analysis has reported that the annual risk of ipsilateral stroke in asymptomatic patients treated medically has decreased from around $2.5 \%$ to less than $1 \%$ over the last two decades [27]. Best medical management in these patients should also consider administering antiplatelet therapy. However, there is very little evidence that antiplatelet therapy is beneficial in preventing stroke or the progression of stenosis in asymptomatic patients [8]. Specifically, one randomized trial of aspirin versus placebo in patients with asymptomatic carotid artery stenosis failed to show any significant long-term protective effect of aspirin therapy [28]. Additionally, a meta-analysis of four primary prevention trials in 'high-risk' patients (some included patients with asymptomatic carotid stenosis), has suggested that the risk-benefit ratio favors antiplatelet therapy (usually monotherapy with aspirin) if the annual baseline risk of myocardial infarction exceeds $1.5 \%$ per year [29]. For this, the US Preventive Services Task Force has recommended daily aspirin as cardiovascular prevention in patients with anticipated cardiac morbidity of $3 \%$ [30]. The most recent AHA guideline for the primary prevention of cardiovascular disease and stroke, in line with the US Preventive Services Task Force, suggests the use of aspirin in persons at high risk, but it recommends a $\geq 10 \%$ risk per 10 years rather than $>3 \%$ risk over 5 years to im- 
prove the likelihood of a positive balance of coronary risk reduction over bleeding and hemorrhagic stroke can be caused by aspirin [31]. There is no evidence to suggest that antiplatelet agents, other than aspirin, can improve benefit in asymptomatic patients with carotid stenosis [9].

Regarding combination antiplatelet therapy, the CHARISMA study, randomized 15,603 high-risk patients for cardiovascular disease to clopidogrel plus aspirin versus aspirin alone and followed them up for a median of 28 months. Of the patients, 3,284 had asymptomatic vascular disease and were included in the study for several reasons, including the presence of $70 \%$ or greater carotid stenosis. In these asymptomatic patients, dual therapy did not reduce the primary endpoint of myocardial infarction, stroke or, cardiovascular death but was associated with an increased risk of cardiovascular death and higher bleeding rates [32]. There is currently no evidence to support the use of combination antiplatelet therapy in patients with asymptomatic carotid stenosis.

\section{Medical Management for the Perioperative Period of Carotid Endarterectomy}

Aspirin therapy alone has been reported to reduce the relative risk of thromboembolic stroke by $20-25 \%$ [33]. Yet, $2-5 \%$ of patients will still suffer an ischemic stroke in the perioperative period [34]. A low dose (81$325 \mathrm{mg}$ ) appears to be more effective then higher doses [35]. Additionally, aspirin must not be discontinued before endarterectomy because the risks of periprocedural myocardial infarction from aspirin withdrawal outweigh the risk of fatal or severe bleeding $[9,36]$. For the above reasons, aspirin should be continued before and after surgery.

Many of the patients undergoing endarterectomy also have previously undergone coronary intervention including drug-eluting stents, which also mandates the use of clopidogrel with aspirin [37]. Furthermore, the preoperative administration of clopidogrel and aspirin seems to reduce postoperative embolization [38]. However, patients taking this combined therapy in the perioperative period have been reported to have a $0.4-1.0 \%$ higher risk of major bleeding compared with aspirin alone [39]. For this, the use of clopidogrel in the perioperative is suggested to be decided on a case-by-case basis [9].

\section{Medical Management for the Periprocedural Period of Carotid Stenting}

The MATCH study demonstrated no additional benefit from the combination of aspirin and clopidogrel compared with clopidogrel alone; instead this combination was shown to increase bleeding complications in the prevention of stroke [40]. Nonetheless, the current practice utilizes dual antiplatelet therapy prior to and after carotid stenting $[14,41]$. Specifically, no randomized trial is yet to compare carotid stenting with dual-antiplatelet therapy versus aspirin alone. However, the CARESS study showed a significant reduction in microemboli in patients treated with dual antiplatelet therapy [23]. Moreover, reductions in the rates of periprocedural stroke, myocardial infarction, and death in published clinical trials to date have been seen with the combination therapy [9]. In fact, in the ICSS and EVA-3S studies [42, 43], the use of dual antiplatelet therapy was recommended but not required. In fact, in EVA-3S, $17 \%$ of patients were not on dual antiplatelet therapy prior to the procedure, and nearly $15 \%$ did not take this combination after procedure. In the CREST study [44], the use of dual antiplatelet therapy was required [45].

Currently, there is no evidence in which to suggest a required length for dual antiplatelet therapy. Despite this, generally in the current practice, dual antiplatelet therapy is initiated at least 3 days before carotid stenting and continued for 1 month after the procedure, whereas aspirin is continued indefinitely $[9,46]$.

\section{Future Perspectives}

Given that great advances, which have significantly reduced the incidence of cerebrovascular disease, have been made over the last 20 years in medical therapy for the prevention of stroke, it is plausible that the benefits of medical therapy outweigh the benefits of surgery in patients with carotid stenosis. To determine such hypothesis, we need to directly compare medical therapy, especially antiplatelet, to surgery. The European Carotid Surgery Trial 2 (ECST-2) (ISRCTN 97744893) is an international randomized trial investigating the optimal treatment in patients with symptomatic or asymptomatic moderate or severe carotid stenosis at low or intermediate risk of future stroke. The trial is comparing the risks and benefits of treatment using current optimized medical management alone versus the addition of immediate carotid surgery (or stenting).
Paciaroni/Bogousslavsky 


\section{Conclusions}

There is inadequate evidence supporting the idea that antiplatelet therapy is beneficial in preventing stroke in asymptomatic patients. However, evidence in favor of using antiplatelet therapy for secondary prevention of recurrent stroke in symptomatic patients with carotid atherosclerosis is more convincing. Regarding patients undergoing carotid endarterectomy, perioperative antithrombotic therapy should consist of aspirin alone, while the addition of clopidogrel should be considered for highrisk patients. Finally, patients undergoing carotid stenting should be administered with perioperative aspirin and clopidogrel.

\section{References}

$>1$ Paciaroni M, Silvestrelli G, Caso V, Corea F, 13 Shrikhande GV, McKinsey JF: Choosing the Venti M, Milia P, Tambasco N, Parnetti L, Gallai V: Neurovascular territory involved in different etiological subtypes of ischemic stroke in the Perugia Stroke Registry. Eur J Neurol 2003;10:361-365.

-2 Bogousslavsky J, Van Melle G, Regli F: The Lausanne Stroke Registry: analysis of 1,000 consecutive patients with first stroke. Stroke 1988;19:1083-1092.

$>3$ Wolff T, Guirguis-Blake J, Miller T, Gillespie M, Harris R: Screening for carotid artery stenosis: an update of the evidence for the US Preventive Services Task Force. Ann Intern Med 2007;147:860-870.

$>4$ De Weerd M, Greving JP, Hedblad B, et al: Prevalence of asymptomatic carotid artery stenosis in the general population: an individual participant data meta-analysis. Stroke 2010;41:1294-1297.

$>5$ Taussky P, Hanel RA, Meyer FB: Clinical considerations in the management of asymptomatic carotid artery stenosis. Neurosurg Focus 2011;31:E7.

-6 Mathiesen EB, Joakimsen O, Bonaa KH: Prevalence of and risk factors associated with carotid artery stenosis: the Tromso Study. Cerebrovasc Dis 2001;12:44-51.

7 Redgrave JN, Rothwell PM: Asymptomatic carotid stenosis: what to do. Curr Opin Neurol 2007;20:58-64.

8 Ederle J, Brown MM: The evidence for medicine versus surgery for carotid stenosis. Eur J Radiol 2006;60:3-7.

$>9$ Ricotta JJ, AbuRahma A, Ascher E, Eskandari M, Faries P, Lal BK: Updated Society for Vascular Surgery guidelines for management of extracranial carotid disease. J Vasc Surg 2011; 54:e1-e31.

10 Touzé E: Treatment of carotid stenosis. Curr Vasc Pharmacol 2012;10:734-738.

-11 Rothwell PM, Eliasziw M, Gutnikov SA, et al: Endarterectomy for symptomatic carotid stenosis in relation to clinical subgroups and timing of surgery. Lancet 2004;363: 915-924.

>12 Barnett HJ, Taylor DW, Eliasziw M, et al: Benefit of carotid endarterectomy in patients with symptomatic moderate or severe stenosis. North American Symptomatic Carotid Endarterectomy Trial Collaborators. N Engl J Med 1998;339:1415-1425. appropriate intervention for symptomatic and asymptomatic carotid disease in the era of multiple therapies: integration of risk profile and technical data. Semin Vasc Surg 2011;24:53-59.

14 Ritter JC, Tyrrell MR: The current management of carotid atherosclerotic disease: who, when and how? Interact Cardiovasc Thorac Surg 2013;16:339-346.

15 Hodis HN, Mack WJ, LaBree L, et al: Reduction in carotid arterial wall thickness using lovastatin and dietary therapy: a randomized controlled clinical trial. Ann Intern Med 1996;124:548-556.

16 MacMahon S, Sharpe N, Gamble G, et al: Effects of lowering average of below-average cholesterol levels on the progression of carotid atherosclerosis: results of the LIPID Atherosclerosis Substudy. Circulation 1998;97: 1784-1790.

$>17$ Youssef F, Seifalian AM, Jagroop IA, et al: The early effect of lipid-lowering treatment on carotid and femoral intima media thickness (IMT). Eur J Vasc Endovasc Surg 2002;23: 358-364.

18 Heart Protection Study Collaborative Group: MRC/BHF Heart Protection Study of cholesterol lowering with simvastatin in 20,536 high-risk individuals: a randomised placebocontrolled trial. Lancet 2002;360:7-22.

$>19$ Amarenco P, Bogousslavsky J, Callahan A III, et al: High-dose atorvastatin after stroke or transient ischemic attack. N Engl J Med 2006; 355:549-559.

20 Rothwell PM, Howard SC, Spence JD: Relationship between blood pressure and stroke risk in patients with symptomatic carotid occlusive disease. Stroke 2003;34;2583-2590.

21 Antithrombotic Trialists Collaboration: Collaborative meta-analysis of randomised trials of antiplatelet therapy for prevention of death, myocardial infarction, and stroke in

22 O'Donnell MJ, Hankey GJ, Eikelboom JW: Antiplatelet therapy for secondary prevention of noncardioembolic ischemic stroke: a critical review. Stroke 2008;39:1638-1646.

23 Markus HS, Groste DW, Kaps M, et al: Dual antiplatelet therapy with clopidogrel and aspirin in symptomatic carotid stenosis evaluated using Doppler embolic signal detection: the Clopidogrel and Aspirin for Reduction of high risk patients. BMJ 2002;324:71-86.
Emboli in Symptomatic Carotid Stenosis (CARESS) trial. Circulation 2005;111:22332240.

24 Wang Y, Wang Y, Zhao X, Liu L, Wang D, Wang C, Wang C, Li H, Meng X, Cui L, Jia J, Dong Q, Xu A, Zeng J, Li Y, Wang Z, Xia H, Johnston SC: Clopidogrel with aspirin in acute minor stroke or transient ischemic attack. N Engl J Med 2013;369:11-19.

25 Mohr JP, Thompson JL, Lazar RM, Levin B, Sacco RL, Furie KL, et al: A comparison of warfarin and aspirin for the prevention of recurrent ischemic stroke. N Engl J Med 2001; 345:1444-1451.

26 Halkes PH, van Gijn J, Kappelle LJ, Koudstaal PJ, Algra A: Medium intensity oral anticoagulants versus aspirin after cerebral ischemia of arterial origin (ESPRIT): a randomised controlled trial. Lancet Neurol 2007;6:115-124.

27 Abbott AL: Medical (nonsurgical) intervention alone is now best for prevention of stroke associated with asymptomatic severe carotid stenosis: results of a systematic review and analysis. Stroke 2009;40:e573-e583.

28 Cote R, Battista RN, Abrahamowicz M, et al: Lack of effect of aspirin in asymptomatic patients with carotid bruits and substantial carotid narrowing. The Asymptomatic Cervical Bruit Study Group. Ann Intern Med 1995; 123:649-655

29 Patrono C, Garcia Rodriguez LA, Landolfi R, Baigent C: Low-dose aspirin for the prevention of atherothrombosis. N Engl J Med 2005; 353:2373-2383.

30 Wolff T, Miller T, Ko S: Aspirin for the primary prevention of cardiovascular events: an update of the evidence for the US Preventive Services Task Force. Ann Intern Med 2009; 150:405-410.

31 Goldstein LB, Bushnell CD, Adams RJ, Appel LJ, Braun LT, Chaturvedi S, Creager MA, Culebras A, Eckel RH, Hart RG, Hinchey JA, Howard VJ, Jauch EC, Levine SR, Meschia JF, Moore WS, Nixon JV, Pearson TA: Guidelines for the primary prevention of stroke: a guideline for healthcare professionals from the American Heart Association/American Stroke Association. Stroke 2011;42:517-584.

32 Bhatt DL, Fox KA, Hacke W, et al: Clopidogrel and aspirin versus aspirin alone for the prevention of atherothrombotic events. N Engl J Med 2006;354:1706-1717.
Antithrombotic Therapy in Carotid

Artery Stenosis: An Update 
33 Collaborative overview of randomised trials of antiplatelet therapy - I: prevention of death, myocardial infarction, and stroke by prolonged antiplatelet therapy in various categories of patients. Antithrombotic Trialists' Collaboration. BMJ 1994;308:81-106.

\34 Barnett HJ, Eliasziw M, Meldrum HE: Drugs and surgery in the prevention of ischemic stroke. N Engl J Med 1995;332:238-248.

35 Taylor DW, Barnett HJM, Haynes RB, Ferguson GG, Sackett DL, Thorpe KE, et al: Lowdose and high-dose acetylsalicylic acid for patients undergoing carotid endarterectomy: a randomised controlled trial. ASA and Carotid Endarterectomy (ACE) Trial Collaborators. Lancet 1999;353:2179-2184.

36 Merritt JC, Bhatt DL: The efficacy and safety of perioperative antiplatelet therapy. J Thromb Thrombolysis 2004;17:21-27.

37 McKinsey JF: Symptomatic carotid stenosis: endarterectomy, stenting, or best medical management? Semin Vasc Surg 2008;21:108-114.
38 Payne DA, Jones CI, Hayes PD, Thompson MM, London NJ, Bell PR, Goodall AH, Naylor AR: Beneficial effects of clopidogrel combined with aspirin in reducing cerebral emboli in patients undergoing carotid endarterectomy. Circulation 2004;109:1476-1481.

39 Eikelboom JW, Hirsh J: Bleeding and management of bleeding. Eur Heart J Suppl 2006; 8(suppl G):G38-G45.

40 Diener HC, Bogousslavsky J, Brass LM, Cimminiello C, Csiba L, Kaste M, et al; MATCH Investigators: Aspirin and clopidogrel compared with clopidogrel alone after recent ischaemic stroke or transient ischaemic attack in high-risk patients (MATCH): randomised, double-blind, placebo-controlled trial. Lancet 2004;364:331-337.

41 McKevitt FM, Randall MS, Cleveland TJ, Gaines PA, Tan KT, Venables GS: The benefits of combined anti-platelet treatment in carotid artery stenting. Eur J Vasc Endovasc Surg 2005;29:522-527.
42 Ederle J, Dobson J, Featherstone RL, et al: Carotid artery stenting compared with endarterectomy in patients with symptomatic carotid stenosis (International Carotid Stenting Study): an interim analysis of a randomised controlled trial. Lancet 2010;375:985-997.

43 Mas JL, Chatellier G, Beyssen B, et al: Endarterectomy versus stenting in patients with symptomatic severe carotid stenosis. $\mathrm{N}$ Engl J Med 2006;355:1660-1671.

44 Brott TG, Hobson RW, Howard G, et al: Stenting versus endarterectomy for treatment of carotid-artery stenosis. N Engl J Med 2010; 363:11-23.

45 Lovrencic-Huzjan A, Rundek T, Katsnelson M: Recommendations for management of patients with carotid stenosis. Stroke Res Treat 2012;2012:175869.

46 Chaturvedi S, Yadav JS: The role of antiplatelet therapy in carotid stenting for ischemic stroke prevention. Stroke 2006;37:15721577. 